\title{
Comentarios
}

\section{A propósito del anteproyecto de ley del presupuesto general de la nación para el 2001}

A principios de la década de 1990, un examen retrospectivo del comportamiento del presupuesto reflejaba que este había experimentado cambios importantes en su composición: si durante la década de 1970 se observaba que el Estado daba mayor importancia al gasto social al asignar cerca del 6 por ciento del producto interno bruto (PIB) para gasto social, a principios de la década de 1990 era evidente que los recursos destinados a estos sectores habían menguado su participación en el producto interno bruto pasando a niveles de 3.8 por ciento, en 1994. La razón de este cambio fue la reasignación del gasto público para favorecer los gastos en defensa y seguridad pública, en respuesta a la conflictividad que caracterizó el período 1979-1992; la defensa y seguridad pública pasaron de recibir 1.4 por ciento del producto interno bruto, en 1974, a 3.4 por ciento, en 1981, y 2.4 por ciento, en 1994.

En los albores del siglo XXI, la situación no ha cambiado sensiblemente y aunque las asignaciones para gasto social se han elevado hasta representar 4.7 por ciento del producto interno bruto, aún persisten elevados gastos asociados a la conflictividad social. De hecho, aunque la guerra civil finalizó en 1992, aún en el año 2000 se resienten los elevados gastos en seguridad pública, administración de justicia e, inclusive, la defensa nacional, los cuales llegan a representar en conjunto un total del 3 por ciento del producto interno bruto.

A finales de septiembre pasado se conocieron las primeras propuestas del anteproyecto de ley del presupuesto general de la nación para el año 2001, que deberán ser discutidas por los diputados de la
Asamblea Legislativa. Estas continúan reflejando la tendencia ya mencionada antes, así como otras relativamente nuevas, pero que amenazan con volverse más permanentes: elevados niveles de servicio de la deuda externa, incremento del financiamiento a los gobiernos municipales, contracción de los gastos asignados para aquellos entes públicos dedicados a la promoción del crecimiento económico (ministerios de agricultura y ganadería, economía y hacienda) y, finalmente, tendencias hacia la profundización del déficit fiscal. Es precisamente en este último aspecto donde se encuentra la mayor debilidad de las finanzas públicas, pues pese a la reforma tributaria implementada durante toda la década de 1990, aún no se logra eliminar el déficit fiscal y para el 2001 incluso se espera un incremento del mismo.

En lo que sigue se analiza el anteproyecto de ley del presupuesto general de la nación para el 2001, poniendo especial énfasis en los aspectos recién reseñados para argumentar sobre la necesidad de que se continúe incrementando el gasto social, pero que al mismo tiempo también se incremente y reoriente el gasto en las áreas de apoyo al crecimiento económico, se reduzcan los gastos en defensa y se busquen nuevas fuentes de ingresos tributarios.

Lo primero que habría que destacar de la propuesta de ley del presupuesto para el 2001 sería el hecho de que se ha suscitado un nuevo incremento en el gasto social, especialmente de los gastos asignados a educación y salud que, entre el 2000 y 2001 , experimentarán incrementos de 10.8 y 8 por 
ciento, respectivamente. Así, el presupuesto conjunto de los dos rubros hacen un total respetable de 30.74 por ciento del presupuesto propuesto para el 2001, lo cual implica un incremento en relación con el 29.52 por ciento asignado en el 2000 , y más todavía si lo comparamos con el 23 por ciento asignado en 1996. Los presupuestos de los dos restantes ramos del área social (trabajo y vivienda y desarrollo urbano) han sufrido recortes que, sin embargo, son poco significativos. El presupuesto asignado al Ministerio de Trabajo pasaría del 0.34 al 0.32 por ciento, entre el año 2000 y el 2001, mientras que el presupuesto asignado al Viceministerio de Vivienda habría pasado de 0.29 a 0.24 por ciento, en los mismos años. En total, el gasto social pasaría de 30.2 a 31.2 por ciento, lo cual no es un incremento espectacular, pero viene a sumarse a las tendencias de los últimos años. Con todo, no debe olvidarse que como se señaló al principio, el gasto social en relación con el producto interno bruto todavía se encuentra por debajo de los niveles alcanzados a mediados de la década de 1970.

En lo tocante al gasto en defensa y seguridad pública, llama la atención el que se proyecta una reducción del 2.55 por ciento en el ramo de defensa, pero un incremento del 1.54 por ciento en el ramo de seguridad pública y justicia. En la práctica, ello estaría implicando reducir la participación total de estos gastos en el presupuesto desde el 13.94 por ciento en el 2000 al 13.2 por ciento en el 2001. Los gastos en estos rubros han venido cayendo durante la década de 1990, pero aún se encuentran a niveles relativamente altos si los comparamos con la década de 1970, cuando apenas superaban el 7 por ciento del total del presupuesto. A los gastos anteriores se agregan otros relacionados con la administración de justicia, como el presupuesto para el Órgano Judicial, Fiscalía General y Procuraduría General, que sumarían un total del 6.6 por ciento del presupuesto del 2001. Es decir que, en total, el 19.8 por ciento del presupuesto del 2001 se gastaría en mantener el status quo a través de la coerción (defensa, seguridad pública y administración de justicia), lo cual es, a todas luces, un monto demasiado elevado para este rubro y refleja que, pese a la finalización del conflicto armado, persisten elevados niveles de conflictividad social.

En relación con el tema de la deuda pública, es importante destacar que esta ha mantenido una importante participación en la composición del presupuesto, práclicamente a lo largo de toda la déca- da de 1990. Para el 2001, se proyecta que el 15.85 por ciento del total del presupuesto se dedique al servicio de la misma, lo cual representa cerca del 50 por ciento más de lo asignado a la rama de salud. Sin duda que al analizar el tema de la deuda, debe tomarse en cuenta que aunque el servicio de ésta representa una carga fiscal que resta recursos que podrían dedicarse a otros rubros, la contratación de empréstitos también es importante $\longrightarrow$ hasta indispensable - para financiar el gasto social o, en otros casos, para financiar la ampliación de la infraestructura vial. Es decir, que si deseamos mayor inversión pública, debemos resignarnos a endeudarnos cada vez más.

De hecho, recientemente se desató una polémica en torno a la contratación de empréstitos internacionales entre el presidente Flores y diputados de la oposición política, especialmente del FMLN, debido al retraso en la ratificación legislativa necesaria para el desembolso de los préstamos. En medio de ella, el presidente Flores ha sostenido que el nivel de endeudamiento externo de El Salvador no es alarmante y, además, que los préstamos son indispensables para impulsar importantes proyectos de dotación de infraestructura social y de transporte. La primera aseveración es discutible si consideramos que el servicio de la deuda pública (que incluye tanto la deuda externa como la interna) absorbería más del 15 por ciento del gasto público del 2001, mientras que la segunda sugiere que para continuar impulsando las políticas sociales es necesario continuar endeudando al país y, por consiguiente, comprometiendo los recursos del Estado para pagar la deuda.

Aunque es de justicia reconocer que en los últimos años la participación del servicio de la deuda pública se ha reducido, también debe reconocerse que al mismo tiempo las obligaciones generales del Estado han venido creciendo, compensando con creces la reducción de la primera. Por ejemplo, entre el 2000 y 2001 se espera que el servicio de la deuda pública se reduzca en un 1.53 por ciento (cerca de 46 millones), pero al mismo tiempo las obligaciones generales se incrementarán en un 36.8 por ciento (cerca de 617 millones de colones), lo cual compensaría con mucho la reducción en la participación del servicio de la deuda pública. Así, aunque no puede negarse que el servicio de la deuda pública ha reducido su participación en el total del presupuesto general (en 1994 representaba 22.03 por ciento, mientras que en el 2001 
representaría sólo el 15.9 por ciento), tampoco puede dejar de notarse que las obligaciones generales del Estado han venido creciendo hasta llegar al 9.56 por ciento en el 2000 ; mientras que para el 2001 se proyecta que este rubro alcance el 12.4 por ciento del total del presupuesto.

Si consideramos ambos rubros, resulta que se gasta el 28.3 por ciento del total del presupuesto en cumplir con las obligaciones financieras del Estado. No sería extraño, entonces, que el incremento de las obligaciones generales sea resultado de la carga fiscal generada por la privatización del sistema de pensiones, lo cual implicaría que esta no ha contribuido a disminuir la carga financiera del Estado - tal como argumentaron sus apologistas-, sino que, todo lo contrario, la incrementó.

El financiamiento de los gobiernos municipales es otro rubro relativamente nuevo que ha elevado su participación en el total del presupuesto. De hecho, para el 2001 se proyecta asignar el 4.67 por ciento del total del presupuesto a este rubro, lo cual, aunque todavía no alcanza el 6 por ciento solicitado por los alcaldes, es una proporción considerable que ha venido a poner mayores presiones sobre el presupuesto. Sin embargo, este rubro ofrece la oportunidad para dedicar una parte del presupuesto al financiamiento de proyectos de desarrollo local, que podrían venir a apoyar el presupuesto destinado al gasto social. No obstante, no queda claro hasta qué punto las alcaldías que reciben financiamiento local satisfacen necesidades sociales de sus municipios con el presupuesto que se les asigna.

En todo caso, la asignación presupuestaria para los gobiernos municipales es una buena medida para apoyar su fortalecimiento que, sin embargo, no obsta para señalar que estos adolecen de graves deficiencias que también' necesitan ser superadas como por ejemplo, escasa capacidad técnica, alta rotación de personal, escasez de recursos y ausencia de planes estratégicos municipales. El apoyo presupuestario del gobierno, a lo sumo, contribuye a lidiar con la problemática de la escasez de recursos.

Otro aspecto que llama la atención al analizar los presupuestos de los últimos dos años, es que los gobiernos no lo han adaptado a las exigencias de la actual situación de lento crecimiento y permanencia de desequilibrios macroeconómicos (en la balanza comercial y finanzas públicas), la cual requiere de una reorientación económica en la cual el Estado debe desempeñar una función importante. Básicamente, el gasto en apoyo al desarrollo

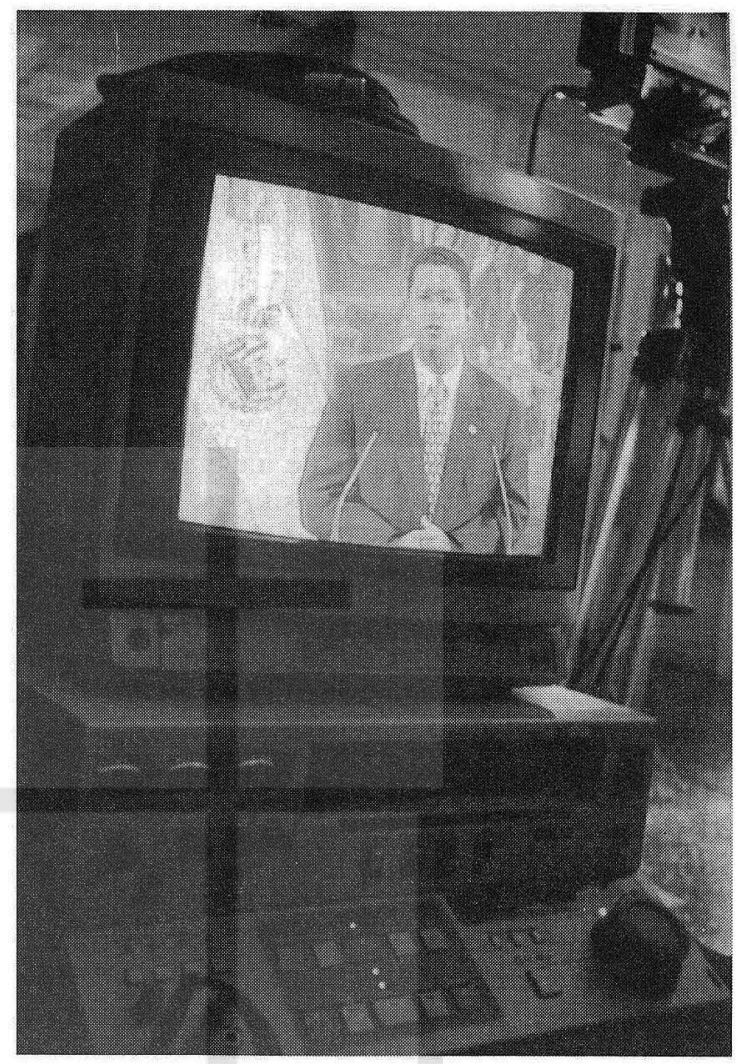

económico puede revisarse a través del comportamiento del presupuesto de los ministerios de agricultura, economía, hacienda y obras públicas, así como del "fondo de estabilización y fomento económico". Estos ramos representaron el 1.99, 1.4, $2.38,5.99$ y 0.83 por ciento, respectivamente, del total del presupuesto del 2000 y se proyecta que representen el $1.6,1.3,1.87,6$ y 0.78 por ciento, respectivamente, del presupuesto del 2001. Lo anterior supone que, prácticamente, todos los rubros (a excepción de obras públicas, que se incrementa en 0.01) experimentarán reducciones. Esto se evidencia en que entre el 2000 y el 2001, el gasto total en apoyo al desarrollo económico pasaría del 12.59 al 11.82 por ciento, respectivamente.

Dentro de lo anterior, lo más destacable es la nueva reducción en el presupuesto del Ministerio de Agricultura y Ganadería, que caería en 49 millones de colones, pues se da precisamente en un momento en que se ejecuta un "plan de reactivación agropecuaria", el cual, sin lugar a dudas, necesita apoyo del citado ministerio. De la misma forma, las disminuciones en los presupuestos de economía y hacienda implican mayores restricciones para el desarrollo 
de tareas relacionadas con la reorientación de la economía, la negociación de tratados comerciales y la obtención de más ingresos fiscales, que financien el creciente presupuesto general de la nación.

Cabe destacar que, además de la reducción de los fondos asignados para el apoyo al desarrollo económico, también se percibe que, en algunos casos, los fondos del Estado no están siendo gastados con efectividad ni siquiera en esta área. Prueba de ello es la creación de un fondo especial para financiar el cultivo del café -cuyos precios internacionales tienen diez años de haberse desplomado-, cuando lo que se necesita es promover la diversificación de la producción agropecuaria hacia rubros con mejores precios y perspectivas en el mercado internacional. De igual forma, la creación de un fondo para financiar la construcción de techo industrial implica que se utilicen fondos de los contribuyentes para favorecer a empresarios dedicados a la maquila textil.

Además de los aspectos que tienen que ver estrictamente con la distribución del presupuesto, también hay otro tema de fondo: el financiamiento. Durante los últimos años, el presupuesto ha experimentado un incremento constante (sólo entre 1997 y 2000 se incrementó en un 19.1 por ciento), que no ha sido compensado con un incremento similar o de mayor magnitud de los ingresos tributarios. Como resultado de lo anterior, el déficit fiscal del gobierno central aún no ha podido ser superado y para el 2001 , inclusive, se espera un incremento del mismo que lo llevaría a alcanzar un 2 por ciento del producto interno bruto para ese año, pese a que entre el 2000 y 2001 se espera un incremento del 4.8 por ciento en los ingresos totales del Estado.

En este contexto, llama fuertemente la atención que la reforma tributaria que se ha implementado durante la década de 1990, no haya contribuido significativamente a eliminar el déficit fiscal. En parte, esto se debe a la ya mencionada tendencia alcista del presupuesto de la nación, así como al hecho de que la reforma tributaria introdujo nuevos impuestos, al mismo tiempo que eliminaba antiguos, lo cual, obviamente, redujo el impacto de la reforma sobre los ingresos tributarios. Por ejemplo, la reforma supuso la introducción del impuesto al valor agregado, pero también la eliminación de los impuestos a las exportaciones y al patrimonio, la reducción a la mitad del impuesto a la renta de las empresas, la reducción de los aranceles, etc. En la práctica, la reforma tributaria pareciera ha- ber estado más orientada a reducir la carga tributaria del sector empresarial, que a crear opciones viables para superar el déficit fiscal.

Entre el 2000 y 2001, el gobierno proyecta una reducción en la carga tributaria, que pasaría desde un 12.1 a un 11.5 por ciento del producto interno bruto, lo cual implica que se perdería capacidad para recolectar impuestos, lo que sería algo inaceptable en un contexto de crecientes demandas socioeconómicas y de incrementos constantes en el monto del presupuesto. No se trata de decir, empero, que deba hacerse un incremento generalizado en la recolección de impuestos, sino más bien que deben estudiarse las opciones más viables y equitativas para incrementar los ingresos tributarios.

Recapitulando, puede mencionarse que existen señales positivas en cuanto a que se han incrementado el gasto social y el financiamiento a los gobiernos municipales, pero negativas en cuanto a que se percibe una asignación considerable a las áreas relacionadas con la seguridad ciudadana, se ha reducido el apoyo al crecimiento económico, se incrementan las obligaciones generales del Estado y se profundiza el desequilibrio fiscal. Lo anterior nos lleva a plantear dos interrogantes: ¿qué tan sostenible es una sociedad que debe gastar lo mismo en aspectos sociales que en los aspectos de coerción de la población? Y, ¿qué tan posible es incrementar el gasto a partir de una base tributaria que ya ha demostrado sus debilidades?

La distribución del presupuesto está mostrando que en el país aún existen graves contradicciones sociales, que se manifiestan en actos de violencia que requieren de una participación cada vez mayor del Estado, en aras de mantener el llamado "Estado de derecho". Así, aunque el Estado desarrollara programas amplios de compensación social, es evidente que existen contradicciones fundamentales en el modelo económico y social que es necesario descubrir y erradicar. Un elemento esencial para lograrlo es que, en definitiva, el Estado desarrolle un papel protagónico en al menos dos áreas esenciales: el apoyo al crecimiento económico y el fortalecimiento de los programas de desarrollo social. Inevitablemente, esto nos lleva a plantear que deben buscarse nuevas fuentes de financiamiento para el mayor gasto público que ello implicaría, lo cual necesariamente pasa por un incremento en los impuestos, lo cual podría requerir de una contrarreforma tributaria, que cuestione las medidas adoptadas por anteriores gobiernos, es decir, que incremen- 
te los impuestos cobrados al sector empresarial. Por ejemplo, podría pensarse en regresar la tasa del impuesto sobre la renta de las empresas a su nivel anterior que, como ya se dijo antes, se redujo a la mitad sin ninguna justificación valedera.

Mientras no se alleguen mayores recursos a las arcas del Estado, más lejos estaremos de eliminar los cuellos de botella que obstaculizan el desarrollo económico y social, pues no se contará con los recursos necesarios para incrementar de forma sostenida y simultánea los gastos del área social y apoyo al desarrollo económico. Así, aunque el discurso gubernamental propugne por una reducción de la participación del Estado, la realidad muestra que es necesario que este eleve su perfil y una forma de hacerlo es revisando los montos y la distribución del presupuesto general de la nación.

En este contexto, es recomendable que los gobiernos se interesen más por la planificación económica y social, pues aunque pueda ser un tema tabú para muchos funcionarios públicos, es totalmente necesaria para articular los esfuerzos dispersos - y hasta incoherentes- que se realizan en aras del desarrollo.

Asignaciones presupuestarias, según el anteproyecto de ley del presupuesto general de la nación

\begin{tabular}{|c|c|c|c|c|c|}
\hline Unidades primarias & Monto 2000 & Porcentaje & Monto 2001 & Porcentaje & Incremento (\%) \\
\hline Órgano Legislativo & 136.40 & 0.78 & 161.60 & 0.87 & 18.48 \\
\hline Órgano Judicial & 892.30 & 5.08 & 945.00 & 5.10 & 5.91 \\
\hline Órgano Ejecutivo & $10,759.70$ & 61.23 & $11,237.90$ & 60.63 & 4.44 \\
\hline Presidencia & 376.60 & 2.14 & 376.70 & 2.03 & 0.03 \\
\hline Ministerio de Hacienda & 417.40 & 2.38 & 346.20 & 1.87 & $(17.06)$ \\
\hline Ministerio de Rel. Ext. & 234.50 & 1.33 & 210.60 & 1.14 & (10.19) \\
\hline Defensa Nacional & 980.30 & 5.58 & 955.30 & 5.15 & $(2.55)$ \\
\hline Ministerio del Interior & 270.70 & 1.54 & 297.50 & 1.60 & 9.90 \\
\hline Seguridad Pública y Justicia & $1,468.40$ & 8.36 & $1,490.80$ & 8.04 & 1.53 \\
\hline Ministerio de Educación & $3,386.20$ & 19.27 & $3,752.40$ & 20.24 & 10.81 \\
\hline Ministerio de Salud & $1,801.40$ & 10.25 & $1,946.10$ & 10.50 & 8.03 \\
\hline Ministerio de Trabajo & 60.00 & 0.34 & 60.00 & 0.32 & 0.00 \\
\hline Vivienda y Desarrollo Urbano & 50.20 & 0.29 & 44.10 & 0.24 & $(12.15)$ \\
\hline Ministerio de Economía & 236.30 & 1.34 & 250.10 & 1.35 & 5.84 \\
\hline Ministerio de Agricultura & 350.60 & 1.99 & 301.20 & 1.62 & $(14.09)$ \\
\hline Ministerio de Obras Públicas & $1,051.90$ & 5.99 & $1,128.00$ & 6.09 & 7.23 \\
\hline Medio Ambiente y Recursos Naturales & 29.60 & 0.17 & 35.50 & 0.19 & 19.93 \\
\hline Transporte & 45.60 & 0.26 & 43.40 & 0.23 & $(4.82)$ \\
\hline Ministerio Público & 309.60 & 1.76 & 313.70 & 1.69 & 1.32 \\
\hline Fiscalía General & 166.80 & 0.95 & 170.70 & 0.92 & 2.34 \\
\hline Procuraduría General & 110.94 & 0.63 & 111.10 & 0.60 & 0.14 \\
\hline Procuraduría para la Defensa de los Derechos Humano & 31.90 & 0.18 & 31.90 & 0.17 & 0.00 \\
\hline Otras instituciones & 311.50 & 1.77 & 275.90 & 1.49 & (11.43) \\
\hline Corte de Cuentas & 125.30 & 0.71 & 145.00 & 0.78 & 15.72 \\
\hline Tribunal Supremo Electoral & 147.30 & 0.84 & 92.00 & 0.50 & $(37.54)$ \\
\hline Tribunal del Servicio Civil & 1.20 & 0.01 & 1.20 & 0.01 & 0.00 \\
\hline Consejo Nacional de la Judicatura & 37.70 & 0.21 & 37.70 & 0.20 & 0.00 \\
\hline Subtotal instituciones & $12,409.50$ & 70.61 & $12,934.10$ & 69.78 & 4.23 \\
\hline Deuda Pública & $2,983.10$ & 16.97 & $2,937.50$ & 15.85 & $(1.53)$ \\
\hline Obligaciones generales & $1,679.70$ & 9.56 & $2,297.20$ & 12.39 & 36.76 \\
\hline Financiamiento a gobiernos municipales & 739.50 & 4.21 & 866.50 & 4.67 & 17.17 \\
\hline FIS 145.00 & 145.00 & 0.83 & 59.10 & 0.32 & $(59.24)$ \\
\hline Financ. XIX juegos & & 0.00 & 30.40 & 0.16 & \\
\hline Otras transferencias & 267.50 & 1.52 & 267.50 & 1.44 & 0.00 \\
\hline Totales & $18,224.30$ & 100.00 & $19,392.30$ & 100.00 & 6.41 \\
\hline
\end{tabular}

Fuente: Ministcrio de Hacienda. 